\title{
Metallic Contamination in Sediments: coupling experimental approach, isotope geochemistry and geographic information systems (GIS)
}

\author{
AnNe-Marie Desaulty ${ }^{1}$, SEBASTIEN PERRET ${ }^{1}$, \\ MATHIEU THAUVIN ${ }^{2}$, PHILIPPE BATAILARD ${ }^{1}$, ROMAIN \\ MILLOT $^{1}$ \\ ${ }^{1}$ BRGM - French Geological Survey, Orléans, France \\ ${ }^{2}$ ANTEA, Olivet, France
}

This work is a multidisciplinary project whose objective was to understand the mechanisms that control the distribution of metallic contaminants between river waters and sediments from areas identified as potentially at risk on a regional scale. The experimental approach and the triple mineralogical/organic/isotopic characterization were at the heart of this project whose objectives were 1 / to characterize the organic and inorganic carrier phases of metals $(\mathrm{Pb}-\mathrm{Zn}-\mathrm{Cu}-$ $\mathrm{Ni}-\mathrm{Cd}-\mathrm{Cr}$ ) in sediments; 2/ to understand the processes of remobilization of these metal contaminants due to changes in environmental conditions during the resuspension of sediments (dredging of rivers and canals for example); $3 /$ to characterize the isotopic fractionations $(\mathrm{Zn}, \mathrm{Cu})$ induced during these processes.

The main results of this research project are

$1 /$ to have established vulnerability and pressure maps on the scale of the Centre-Val de Loire Region in France, which correspond to zones of strong sedimentary accumulations (vulnerability) associated with the presence of metals (pressure), and

2/ to have developed a chemical and isotopic diagnostic methodology for the characterization of sediments with anthropogenic affluence and to have constrained the mobility of these metals. 